\title{
USO DE IMPLANTES ANGULADOS NA REABILITAÇÃO ORAL: PLANEJAMENTO REVERSO
}

\section{USE OF ANGLED IMPLANTS IN ORAL REHABILITATION: REVERSE PLANNING}

\author{
Luciano Bonatelli Bispo* \\ Caleb David Willy Moreira Shitsuka*
}

\section{RESUMO}

A revolução proporcionada pela descoberta do fenômeno da osseointegração trouxe alternativas antes inimagináveis na reabilitação oral. O uso de fixações com diferentes diâmetros, comprimentos, superfícies, conexões e angulações torna a prática clínica extremamente resolutível nas diversas condições clínicas rotineiramente enfrentadas. Nesse contexto, a disponibilidade óssea é que guia o tipo de reabilitaç̧ão a ser indicada. Muitas vezes, enxertos ósseos e mesmo de tecido conjuntivo, são alternativas necessárias e bastante comuns. No entanto, na tentativa de causar menor morbidade ao paciente, diminuir o tempo clínico e mesmo tornar a reabilitação menos onerosa, implantes angulados proporcionam inúmeras vantagens. Desviar de estruturas anatômicas nobres como nervos e forames, buscar osso em maior quantidade e qualidade, bem como diminuir o tamanho do cantiléver distal, são algumas das indicações favoráveis ao emprego das fixações anguladas. $\mathrm{O}$ objetivo deste trabalho foi fazer uma revisão sobre os aspectos relacionados ao uso de implantes inclinados, suas indicações e contraindicações mais corriqueiras no consultório odontológico.

Descritores: Implantes Dentários • Próteses e Implantes • Prótese Maxilofacial

\section{ABSTRACT}

The revolution brought by the discovery of the osseointegration phenomenon has brought alternatives previously unimaginable in oral rehabilitation. The use of fixations with different diameters, lengths, surfaces, connections and angulations makes the clinical practice extremely resolvable in the diverse clinical conditions routinely faced. In this context, bone availability guides the type of rehabilitation to be indicated. Often, bone grafts and even connective tissue are necessary and quite common alternatives. However, in an attempt to cause less patient morbidity, decrease clinical time and even make rehabilitation less expensive, angled implants provide numerous advantages. To deviate from noble anatomical structures such as nerves and foramina, to obtain bone in greater quantity and quality, as well as to reduce the size of the distal cantilever, are some of the indications favorable to the use of the angular fixations. The aim of this study was to review the aspects related to the use of inclined implants, their indications and more common contraindications in the dental office.

Descriptors: Dental Implants $\bullet$ Prostheses and Implants $\bullet$ Maxillofacial Prosthesis 


\section{N T RO DUÇÃO}

O advento dos implantes endósseos e do fenômeno da osseointegração suscitou alternativas extremamente favoráveis na prática reabilitadora oral. As próteses muco-suportadas, bem como as dento-muco-suportadas nem sempre apresentam retenção e estabilidade adequadas. Levando-se em conta, também, a reabsorção óssea inexorável que ocorre subjacente à área basal ou chapeável dessas próteses, necessitando de controles periódicos, reembasamentos frequentes, trocas esporádicas e insatisfação psicológica dos pacientes ${ }^{1}$.

Pacientes desdentados totais e parciais, em estudos longitudinais e acompanhamentos de longo prazo, têm demonstrado taxa de sobrevida das reabilitações implanto-suportadas com próteses fixas totais e parciais entre 95,5 e $97,9 \%{ }^{2}$. Nos desdentados totais, o desenho biomecânico clássico da prótese tipo protocolo ilustrada por Adell at al. ${ }^{3}$, dispõe de 4 a 6 fixações entre os forames mentonianos, na região anterior mandibular, assim como um cantiléver distal bilateral, em substituição à posição anteriormente ocupada pelos dentes posteriores. O mesmo autor ${ }^{3}$ sugeriu, na maxila, de 6 a 8 implantes, com a confecção de uma infraestrutura metálica unida à uma base de resina acrílica e dentes igualmente de resina acrílica, porém polimerizados termicamente.

Maló et al.4, 5, em 2003 e 2005, sugeriram uma técnica conhecida como "All-on-Four", cuja proposta foi evitar enxertos, desviando-se de estruturas nobres e acidentes anatômicos como, por exemplo, o seio maxilar e o forame mentual. Tal técnica utiliza apenas quatro implantes nas reabilitações fixas implanto-suportadas em pacientes desdentados totais, em que as fixações mais distais são anguladas como forma de diminuir o cantiléver distal.

Biomecanicamente há um axioma apontando que a extensão do cantiléver mandibular não seja superior a 18 a 20mm, também na maxila com no máximo 10 a $12 \mathrm{~mm}^{6,7}$. Conforme Duyck et al. ${ }^{8}$, 2000, deve-se considerar não só a extensão do cantiléver, mas as forças também estão na dependência da sua distribuição, da qualidade e quantidade óssea, número, distribuição e inclinação das fixações, biomecânica e rigidez estrutural da prótese e deformação mandibular quando em função. A deformação funcional ou flexão mandibular foi responsável por $40 \%$ das falhas em reabilitações cujos implantes estavam posteriores aos forames mandibulares ${ }^{9}$. Logo, aconselharam que no planejamento reverso de protocolo inferior, os implantes sejam colocados entre os forames mentonianos ou mentuais.

Torna-se claro o planejamento reverso na distribuição dos implantes e na forma da arcada para o sucesso em longo prazo, com a premente necessidade do uso do cantiléver distal, dando estabilidade oclusal à prótese. O formato da arcada determina o implante mais distal em relação ao implante mais anterior. A linha traçada do centro diametral da fixação mais anterior até outra linha que une a face mais distal dos implantes mais posteriores na arcada (mais distais e bilaterais) é denominada distância A-P (distância ântero-posterior). No protocolo convencional de Adell $^{3}$ et al 1981, quando cinco fixações intermentuais são planejadas, o cantiléver não pode ser maior do que 2,5 vezes a distância A-P. Segundo Misch ${ }^{10}$, em 2007, além da distância A-P, fatores de estresse devem ser considerados, como: parafunção, altura coronária, força e função dos músculos mastigatórios, forma do arco e elementos antagonistas, oclusão, entre outros. Caso haja presença deletéria de um desses fatores, o cantiléver está contraindicado, devendo-se recorrer à outra proposta biomecânica ou desenho complementar.

Diante do exposto surge a problemática da indicação dos implantes angulados no planejamento reverso e execução de reabilitações como, por exemplo: fixações retas como no protocolo tradicional de Brånemark ${ }^{3}$ ou anguladas, como nos implantes mais distais da técnica "All-on-Four" ${ }^{\prime 4,5}$ ? Os implantes angulados teriam indicação biomecânica nos planejamentos diários? O objetivo deste trabalho foi fazer uma revisão sobre o uso de implantes inclinados ou angulados na clínica odontológica, descrevendo suas indicações clássicas e contraindicações relativas
BISPO $L B$

SHITSUKA CDWM

USO $D E$

IMPLANTES

ANGULADOS NA

REABILITAÇÃO

ORAL:

PLANEJAMENTO

REVERSO

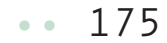

REV, ODONTOL.

UNIV. CID. SÃO

PAULO

2017; 29(2):

$174-83, M A I-A G 0$ 
$B I S P O \quad L B$

SHITSUKA CDWM

USO DE

IMPLANTES

ANGULADOS NA

REABI LITAÇÃO

ORAL:

PLANEJAMENTO

REVERSO

176

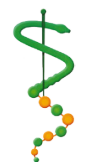

REV, ODONTOL.

UNIV. CID . SÃO

PAULO

2017; 29(2): $174-83$, MAI - AGO e/ou absolutas no planejamento reabilitador contemporâneo.

\section{MÉTODO}

Foram utilizados os indexadores OldMedline e Medline database, no período compreendido entre 1981 e 2016, com os seguintes termos em língua inglesa: implant inclination e dental implants. Para a literatura nacional, utilizou-se o indexador BBO. Da mesma forma, os termos implantes inclinados e implantes dentários foram pesquisados no período de 1981 a 2016. Após leitura de 102 artigos, sem nenhum critério de exclusão, selecionaram-se; posteriormente, 15 artigos que apresentaram maior afinidade com o objetivo proposto. As demais referências foram obtidas por intermédio dos artigos principais selecionados e considerados pertinentes para essa revisão.

\section{REVISÃO DE LITERATURA}

Consoante Per-Ingvar Brånemark (3 de maio de 1929 - 20 de dezembro de 2014), considerado o Pai da Implantodontia, a osseointegração é definida como uma conexão direta, estrutural e funcional entre o osso vivo, maduro e organizado e a superfície maquinada ou texturizada de um implante endósseo de titânio, submetido à carga funcional por um longo período de tempo ${ }^{1,3,11,12}$.

Conforme Migliorança et al. ${ }^{13}$, em 2007, a retenção e a estabilidade são diretamente proporcionais com as características anatômicas do rebordo residual. O rebordo residual tem sua reabsorção potencializada devido aos traumas conferidos pelo uso de próteses totais muco-suportadas. Com isso, problemas alimentares e nutricionais, além de desconforto, geram também comprometimentos sociais, afetivos e psicológicos. Citaram que a mudança da técnica original cirúrgica de instalação das fixações zigomáticas (que também usam implantes inclinados), tornou-as mais simples, rápidas, efetivas e conservadoras, pelo correto planejamento antecipado de exteriorização das fixações em relação à loja do seio maxilar. Propuseram, como forma de postergar ou evitar enxertos, a instalação de implantes angu- lados, desviando-se de áreas nobres e de acidentes anatômicos comuns, como o seio maxilar e o forame mentual.

Krekmanov et al. ${ }^{14}$, em 2000, e Hansen et al. ${ }^{15}$, em 1992, dispuseram que a utilização de implantes osseointegrados angulados é uma opção viável, principalmente em reabilitações de mandíbulas e maxilas atróficas. Essa técnica proporciona redução efetiva de custos, diminuição do tempo de tratamento, bem como minimização consistente diante da morbidade, um tanto comum nas técnicas cirúrgicas reconstrutivas. Afirmaram que a magnitude tensional dos implantes mais distalizados é maior quanto mais inclinação tiverem, ou ainda, quanto maior a extensão distal do cantiléver. Nas próteses fixas implanto-suportadas, as fixações se comportam como estrutura única, tendo em vista a união proporcionada pela infraestrutura metálica fundida parafusada sobre os implantes. Resultantes oblíquas e horizontais decompostas de forças mastigatórias não apresentam magnitude tal a fim de gerar alterações significativas nos tecidos peri-implantares (a rigidez estrutural já mencionada confere essa resistência) .

Em conformidade com o protocolo tradicional de Adell $^{3}$ et al 1981, o procedimento cirúrgico em duas etapas tem sido relacionado com taxas de sucesso de 95 a 99\% em dez anos de acompanhamento, também de acordo com Tabuse et al. ${ }^{16}$, 2014. Tarnow et al. ${ }^{17}$, em 2000, exemplificaram que numa reposição protética para quatro elementos dentários perdidos, em região desdentada anterior, respeitar-se-ão as distâncias biológicas já consagradas na literatura. Tendo-se uma distância intercaninos de $29 \mathrm{~mm}$, com o diâmetro de cada implante repositor de mais ou menos $4 \mathrm{~mm}$, a distância entre implantes contíguos de 3mm; e, entre implante e dente de $2 \mathrm{~mm}$. Todavia, a grande maioria das reabilitações não segue essa simples regra, não havendo espaço adequado para um planejamento tridimensional ideal. Assim, segundo os mesmos autores $^{17}$, duas ou três fixações têm de ser associadas com elementos em cantiléver ou suspensos, para maximização da estética e devolução funcional. Planejando-se pônticos, em próteses múltiplas, haverá 
sobrecarga excessiva nos implantes durante a função mastigatória.

De acordo com Piattelli et al. ${ }^{18}, 1998$, existem falhas precoces e tardias no processo de osseointegração. As precoces advêm logo após o ato cirúrgico e são estritamente relacionáveis à pura osseointegração. As falhas tardias acometem os implantes logo após a confecção da prótese. As tardias possuem duas explicações: perda por infecções e peri-implantites ao redor dos tecidos de suporte e fraturas, problemas de ordem mecânica, principalmente, sobrecarga biomecânica. O que está de acordo com McDermott et al. ${ }^{19}$, que expuseram: além da carga oclusal excessiva, há outros causadores de falhas, como local do implante (anterior, posterior, maxila ou mandíbula), insuficiente número de fixações suportando a prótese, tipo de material de confecção da prótese, diâmetro de implantes menores do que 3,5mm; enfim, todos associados com faIhas tardias sem um planejamento biomecânico adequado ${ }^{8,9}$.

Almeida e Pellizzer ${ }^{20}$, em 2008, descreveram a interessante análise e comparação clínica dos fatores biomecânicos mais influenciáveis no estresse na região interfacial osso/implante. Nesse ínterim, há fortes evidências mecânicas de que a inclinação da cúspide é o fator mais preponderante em relação ao momento de torque em comparação a outros fatores como, por exemplo, a angulação ou inclinação do implante. Tais dados corroboraram a consciência clínica de que uma inclinação de cúspide produz um momento de torque maior, acompanhado do diâmetro do implante; já a inclinação da fixação, bem como o seu comprimento, produziram torque diminuto. Para um aumento de $10^{\circ}$ de inclinação da cúspide, há 30\% de aumento na sobrecarga da prótese sobre implante. Somado a isso, para cada $10^{\circ}$ de aumento na angulação do implante, há um aumento proporcional de 5\% de sobrecarga na prótese sobre implante. Para um deslocamento lingual de $1 \mathrm{~mm}$, há $15 \%$ no aumento de torque e, para cada $1 \mathrm{~mm}$ de deslocamento apical, existem 4\% de aumento no torque. Os autores concluíram que a configuração da mesa oclusal e a inclinação das cúspides das próteses sobre implante têm um significado importantíssimo na transmissão de forças e tensões, bem como no estresse gerado no tecido ósseo peri-implantar ${ }^{21,22}$.

Segundo os autores Pereira et al. ${ }^{23}$, em 2011, estudos laboratoriais de análise fotoelástica e estesiometria, relataram que, quanto maior a angulação dos pilares protéticos, assim também maior o estresse transmitido aos implantes. Em estudo de 14 anos de acompanhamento, clinicamente os componentes angulados podem corrigir posicionamentos errôneos dos implantes sem maiores comprometimentos de sua sobrevida. Afirmaram, ainda, que não existe diferença estatisticamente significante entre componentes protéticos retos e angulados quando avaliados e submetidos a esforços de rotação e deflexão ${ }^{24}$.

Bueno Torcato et al. ${ }^{25}$, em 2016, consideraram que a maioria dos problemas em próteses sobre implantes é de cunho biomecânico. Lembraram a existência de uma perda marginal crônica de $0,9 \mathrm{~mm}$ no primeiro ano e de $0,1 \mathrm{~mm}$ nos anos subsequentes ao redor das fixações (saucerização). Havendo um gap na interface implante/abutment que pode ser causador de inflamação e nicho concentrador de tensões resultantes de diversas magnitudes, inclusive de cargas mastigatórias. Citaram que as conexões internas são superiores às conexões de hexágono externo, em virtude de menores índices de afrouxamento de parafusos ou fratura, distribuindo as tensões homogeneamente e absorvendo com maior naturalidade as sobrecargas. Consequentemente, se a força não é direcionada para o longo eixo do implante, o tecido ósseo cortical absorverá as tensões regionais. Tais observações foram contrárias às feitas por Chun et al. ${ }^{26}$, que empregaram elementos finitos tridimensionais, onde a tensão de Von Mises máxima ocorreu na região do osso compacto adjacente à primeira rosca implantar em todos os tipos de conexão: hexágono externo, interno e corpo-único. Usaram diferentes abutments aplicando carga oblíqua e axial.

Hermann et al. ${ }^{27}, 2007$, relataram que as overdentures ou sobredentaduras proporcionam vantagens: aumentam a retenção nos casos de reabsorção mandibular
BISPO $L B$

SHITSUKA CDWM

USO $D E$

IMPLANTES

ANGULADOS NA

REABILITAÇÃO

ORAL:

PLANEJAMENTO

REVERSO

177

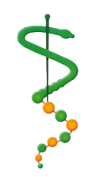

REV, ODONTOL.

UNIV, CID. SÃo

PAULO

2017; 29(2):

$174-83$, MA I - AGO 
$B I S P O \quad L B$

SHITSUKA CDWM

USO DE

IMPLANTES

ANGULADOS NA

REABI LITAÇÃO

ORAL:

PLANEJAMENTO

REVERSO

178

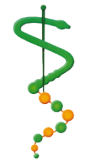

REV, ODONTOL.

UNIV, C I D . SÃO

PAULO

2017; 29(2):

$174-83$, MAI - AGO
I SSN 1983-5183

severa, sustentam os tecidos faciais e periorais pela presença vestibular da flange e possibilitam remoção para facilitada higienização. Apresentam um custo mais popular quando comparadas a outros tipos de reabilitações, pois reduzem o número de implantes e dispensam procedimentos de fundição. Contudo, o posicionamento das fixações deve ser paralelo ${ }^{29,30,31}$, devido ao eixo de inserção, evitando perda de retenção devido ao desgaste prematuro dos componentes ${ }^{28,29}$. Logo, a divergência máxima com a utilização do sistema attachment bola, entre os dois implantes, deve ser de no máximo $10^{\circ}$.

Duailibe-de-Deus et al. ${ }^{30}$, em 2016, revisaram literatura, para descrição de caso clínico, e concluíram que implantes de conexão cone Morse aumentam ou mantêm a altura e a densidade da crista óssea alveolar, exibindo maior garantia de resultado estético, principalmente em região anterior. O posicionamento vestíbulo palatino do implante deve manter pelo menos $1,5 \mathrm{~mm}$ de osso rodeando a circunferência peri-implantar, para uma melhor distribuição de cargas no sentido do seu eixo longitudinal.

Berwanger et al.. ${ }^{31}$, em 2014, elucidaram que a técnica de instalação de implantes inclinados na reabilitação de maxila atrófica tem vantagens, como: menor tempo clínico de tratamento, não é necessário enxerto ósseo; além de diminuição do custo financeiro. Dispõem que a técnica alternativa de cirurgia com aposição de implantes angulados em maxilas atróficas foi tema da $13^{\text {a }}$ Conferência Internacional de Cirurgia Bucomaxilofacial. Desde então, a técnica tem sido sugerida e tem mostrado resultados satisfatórios de acompanhamento clínico a longo prazo. Evidenciaram que a inclinação dos implantes é uma alternativa à transfixação do seio maxilar, pode utilizar implantes mais longos (possibilidade de ancorar os implantes em tecido ósseo de maior e melhor densidade) e diminui o cantiléver distal. A escolha de tal técnica está pautada na falta de volume adequado para instalação em posição ideal ${ }^{32}$, menor tempo quando comparada à enxertia extensa de tecido ósseo ${ }^{33}$ e, por último, a obtenção de próteses mais estáveis ${ }^{34}$ por diminuir as extremidades livres. O mais importante, segundo os mesmos autores, foi a estabilidade primária conseguida com implantes angulados e com carga imediata, fornecendo um previsível aumento do sucesso na resposta biológica tecidual.

\section{I SCUSSÃO}

A oclusão em prótese sobre implante deve ter o mínimo de contatos oclusais, sendo tais contatos bilaterais e simultâneos, sem contatos prematuros para a posição de máxima intercuspidação habitual, movimentos laterais excursivos sem interferência no lado de não-trabalho, bem como forças oclusais distribuídas equitativamente28,31,35. Assim, a prótese sobre implante deve receber os mesmos cuidados que a desejada em dentes naturais; contudo, a interface osso-implante não pode ser responsabilizada pelo desenvolvimento de forças23-27, seja nos contatos deflectivos em máxima intercuspidação habitual como em relação cêntrica, e mesmo naqueles contatos oclusais prematuros2,4-5,35. O elemento dentário apresenta micromovimentos devido à presença do ligamento periodontal, sendo o padrão de forças alterado conforme a localização do dente e da inclinação cuspídea6,7, 10-12, 36. Todavia, os implantes osseointegrados não apresentam essa movimentação, e assim foram sugeridas modificações na inclinação das cúspides para minimizar a sobrecarga35,36. Weinberg21, em 1998, sugeriu uma oclusão cêntrica modificada com 1,5mm de fossa horizontal com a produção de resultantes verticais, sem interferências de forças laterais provenientes da mastigação8,9. Demonstrou, de forma matemática, que o fator mais importante é a inclinação da cúspide quando comparado ao torque produzido (momento). Logo, $10^{\circ}$ de inclinação de uma cúspide produzem um aumento de 30\% maior na distribuição de forças. Consequentemente, quando uma força oclusal é aplicada, a resultante proveniente da decomposição de forças é perpendicular à inclinação da cúspide. Óbvio perceber que a inclinação da cúspide foge do escopo do clínico, contudo, o planejamento reverso da reabilitação deve incluir uma redução cuspídea, tendo 
em vista uma distribuição mais homogênea de forças ao redor do osso circunjacente ao implante21. Tais considerações estão de acordo com o apresentado pelos autores Kaukinen et al.37, em 1996. Esses autores verificaram a quantificação de forças verticais da mastigação através de um desenho oclusal. Empregaram, nesse desenho, cúspides com $33^{\circ}$ e superfície oclusal plana. Compararam: quantidade de força inicial para causar a quebra do alimento, força máxima para causar a quebra do alimento e tensão máxima registrada em nível ósseo. Demonstraram que o desenho oclusal e a inclinação cuspídea têm influência na transferência de forças e no estresse gerado no osso. A força inicial para quebra do alimento foi maior com cúspides com $33^{\circ}$ de inclinação. Preconizaram cúspides reduzidas, pouca profundidade na anatomia da face oclusal e sulcos, fossas e fóssulas extensas13-15. Moraes et al.38, em 2002, corroboraram as afirmações anteriores através da análise de tensões de implantes, variando-se a largura da mesa oclusal, bem como a inclinação das cúspides. Fizeram modelos com pilar Esteticone e coroas com $30^{\circ}$ e $45^{\circ}$ de inclinação cuspídea. Aplicaram carga de $100 \mathrm{~N}$ (Newton) em metade do raio da prótese, analisando a variação angular, com mesma carga em um segmento de $1,55 \mathrm{~mm}$ nas proximidades da coroa protética. Concluíram que o aumento do ângulo da cúspide elevou as tensões nos componentes protéticos, também nas coroas com maior diâmetro de mesa oclusal vestíbulo-lingual, com aumento das tensões na junção pilar-implante. O próprio Misch10, em 2007, escreveu um capítulo de considerações oclusais, mencionando que o ângulo de força sobre o corpo da fixação é influenciado pela inclinação cuspídea. Dentes esculpidos para coroas protéticas e restaurações com cúspides de $30^{\circ}$ têm sido comuns. Ao contrário dos dentes naturais, com cúspides íngremes e bastante inclinadas, que, apesar de incisar melhor o alimento, fornecem resultantes com cargas ao osso da crista. Sendo tal magnitude de forças minimizada, quando não é um contato prematuro, mas uma carga uniforme, distribuída sobre vários elementos. Entretanto, a carga angulada da cúspide aumenta o estresse, sem vantagens aparentes, mas com risco aumentado10, 21, 35, 37. Misch10, em 2007, citou ainda que, quando um implante é carregado no seu longo eixo, não são observadas forças laterais. Um implante com $15^{\circ}$ de angulação permite com facilidade um abutment de $15^{\circ}$ de angulação. Tanto o implantodontista como o técnico de laboratório tratam os implantes, axial e angulado, como semelhantes. Todavia, no implante angulado, aumenta-se em 25,9 $\%$ a carga no osso vestibular. Um implante com ângulo de inclinação de $30^{\circ}$ vai resultar numa direção ao vestíbulo advinda de uma carga oclusal qualquer de $50 \%$ no osso vestibular, por exemplo21,22. Assim, cinco procedimentos tornam-se indispensáveis quando do planejamento reverso das próteses sobre implante quanto à biomecânica: oclusão cruzada sempre que houver possibilidade, cabeça do implante sempre posicionada o mais próximo possível da linha média da restauração, acesso ou paralelismo necessário obtido com intermediários angulados, cúspides inclinadas reduzidas em dentes posteriores e anatomia oclusal em cêntrica em 1,5mm na fossa oclusal18-21.

A associação de implantes largos com diminuição da inclinação das cúspides em coroas implanto-suportadas diminui as tensões nos parafusos de retenção das próteses, prevenindo sua fratura, contrariamente ao que ocorre com implantes inclinados39. Tal fato foi posteriormente confirmado por Akça e Iplikçioğlu40, em 2001, em que os menores valores de estresse foram encontrados em implantes mais largos e posicionados de forma mais linear. Os implantes desalinhados, tanto para vestibular como para lingual em mandíbula edêntula, resultaram em valores similares quanto ao estresse gerado. Assim o implante deslocado não minimiza o estresse, mas somente esse associado com o aumento do seu diâmetro.

As forças oclusais nos implantes osseointegrados dependem de sua localização no arco. Quanto mais para posterior, maiores são os riscos de sobrecarga. Nos arcos maxilares, uma leve inclinação para vestibular é mais aceitável do que uma inclinação lingual. Na mandíbula, uma in-
BISPO $L B$

SHITSUKA CDWM

USO $D E$

IMPLANTES

ANGULADOS NA

REABILITAÇÃO

ORAL:

PLANEJAMENTO

REVERSO

179

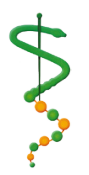

REV, ODONTOL.

UNIV, CID, SÃo

PAULO

2017; $29(2)$ :

$174-83$, MA I - AGO 
$B I S P O \quad L B$

SHITSUKA CDWM

USO DE

IMPLANTES

ANGULADOS NA

REABI LITAÇÃO

ORAL:

PLANEJAMENTO

REVERSO

180

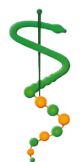

REV, ODONTOL.

UNIV, C I D . SÃO

PAULO

$2017 ; 29(2):$

$174-83$, MAI - AGO clinação mais para lingual é tolerável10. Acredita-se que uma carga oclusal aplicada ao corpo de um implante angulado e que a mesma carga aplicada de forma oblíqua perpendicular ao plano oclusal, produzem resultados semelhantes. As cargas aplicadas em diferentes ângulos são divididas em: normais (compressivas e elásticas) e de cisalhamento. Em elementos finitos, quando a direção de uma força muda para uma carga mais angulada, o estresse é aumentado em sua magnitude em três vezes. Quando componentes elásticos e de cisalhamento sobrepujam as forças puramente compressivas, o estresse é aumentado em mais de 20 vezes 10 .

Gross e Nissan ${ }^{41}$, em 2001, avaliaram a distribuição do estresse ao redor de implantes maxilares empregando um modelo fotoelástico anatômico com múltiplas variantes geométricas ${ }^{16,17}$. Empregaram dois crânios fotoelásticos em que, no primeiro, primaram pelo corte coronal ou frontal em região de primeiro molar, com inclinações entre $0^{\circ}$ e $25^{\circ}$ em relação ao plano sagital mediano, em análogo de metal, na esquerda e na direita mandibulares. No segundo crânio, foi realizado corte vestibular em cilindro embutido em implante posicionado na região do primeiro molar. Foram feitas fotos com carga axial e oblíqua sobre o implante demonstrando a concentração do estresse principal. Concluíram que o osso na vestibular em espessura é desejável para uma resposta fisiológica aos esforços. Pouco volume predispõe a fenestrações e deiscências, potencializando o fracasso peri-implan$\operatorname{tar}^{33,34}$. O que, posteriormente, foi considerado concorde com Çaglar et al. ${ }^{42}$, em 2006, observando o padrão de Von Mises, por elemento finito, em região edêntula maxilar ao redor de prótese fixa implanto-suportada. Em primeira conduta, os implantes foram fixados em osso maxilar, em regiões de primeiro pré-molar, segundo pré-molar e segundo molar. Em segundo lugar, foram posicionados em região de segundo pré-molar, segundo molar e em extensão em cantiléver mesial em espaço de primeiro pré-molar ausente. Na região de segundo molar apresentaram três in- clinações: $0^{\circ}, 15^{\circ}$ e $30^{\circ}$. Carregamentos verticais, oblíquos e horizontais foram realizados. Os maiores valores médios obtidos como resultado foram os obtidos pelo carregamento oblíquo. O osso cortical concentrou o estresse nos três tipos de carregamento. Sendo maior nas áreas vestibular e lingual, no pescoço do implante, do que nas regiões mesial e distal. A região distal, quando comparada à mesial apresentou os maiores valores de estresse, devido à inclinação do implante na área do molar. Na região de pré-molar o estresse no carregamento vertical aumentou 3,5 vezes, quando da configuração com o uso do cantiléver, e duas vezes mais com o carregamento oblíquo e com o horizontal. No modelo em cantiléver, mais uma vez, o estresse ao redor do implante adjacente ao mesmo foi muito maior ${ }^{41,42}$.

\section{CONCLUSÕES}

Na literatura consultada sobre os implantes inclinados ou angulados, depreende-se que:

- São indicados para minimização do tempo operatório, sem a necessidade de enxertos e consequente espera para consolidação e/ou integração óssea;

- Técnica extremamente conservadora, quando comparada a outras técnicas reconstrutivas, favorável numa Odontologia Contemporânea Minimamente Invasiva;

- Menor dispêndio financeiro por parte do paciente;

- Permitem uma ancoragem bicortical em osso mais denso, com maior altura, o que favorece sobremaneira a estabilidade primária e o carregamento imediato;

- Devem, possivelmente, ser evitados biomecanicamente, porém quando indicados (quando não é possível evitar o posicionamento inadequado dos implantes ou nas técnicas para diminuir o cantilever distal), devem ser calcados através de um planejamento reverso criterioso, preferencialmente usando-se implantes inclinados com maior diâmetro, espacialmente bem localizados em relação ao tecido 
ósseo disponível, majoritariamente unidos ou esplintados, com cúspides baixas e pouco inclinadas, plataforma oclusal ampla e ajuste oclusal pormenorizado com con- tatos simultâneos bilaterais, guias de proteção anterior e posterior e ausência de contatos prematuros nos movimentos mandibulares excursivos.

\section{REFERÊNCIAS}

1. Freitas MA, Rocha P. Influência na retenção de coroas cimentadas sobre implantes com e sem orifício ao parafuso. Dental Press Implantol. 2012;6(3):82-90.

2. Rocha SS, Souza DR, Fernandes JMA, Garcia RR, Zavanelli RA. Próteses totais fixas do tipo protocolo bimaxilares. Relato de caso. Revista Odontológica do Brasil Central. 2013;22(60):21-7.

3. Adell R, Lekholm U, Rockler B, Brånemark PI. A 15-year study of osseointegrated implants in the treatment of the edentulous jaw. International journal of oral surgery. 1981;10(6):387-416.

4. Malo P, Rangert B, Nobre M. "All-on-Four" immediate-function concept with Branemark System implants for completely edentulous mandibles: a retrospective clinical study. Clin Implant Dent Relat Res. 2003;5 Suppl $1: 2-9$.

5. Malo P, Rangert B, Nobre M. All-on-4 immediate-function concept with Brånemark System implants for completely edentulous maxillae: a 1-year retrospective clinical study. Clin Implant Dent Relat Res. 2005;7 Suppl 1:S8894.

6. Lundqvist S, Carlsson GE. Maxillary fixed prostheses on osseointegrated dental implants. Journal of Prosthetic Dentistry.50(2):262-70.

7. Lindquist LW, Rockler B, Carlsson GE. Bone resorption around fixtures in edentulous patients treated with mandibular fixed tissue-integrated prostheses. The Journal of prosthetic dentistry. 1988;59(1):59-63.
8. Duyck J, Van Oosterwyck H, Vander Sloten J, De Cooman M, Puers R, Naert I. Magnitude and distribution of occlusal forces on oral implants supporting fixed prostheses: an in vivo study. Clinical oral implants research. 2000;11(5):465-75.

9. Miyamoto Y, Fujisawa K, Takechi M, Momota Y, Yuasa T, Tatehara S, et al. Effect of the additional installation of implants in the posterior region on the prognosis of treatment in the edentulous mandibular jaw. Clinical oral implants research. 2003;14(6):727-33.

10. Misch C. Prótese sobre implantes. São Paulo: Santos; 2007.

11. Friberg B, Grondahl K, Lekholm U, Brånemark PI. Long-term follow-up of severely atrophic edentulous mandibles reconstructed with short Branemark implants. Clin Implant Dent Relat Res. 2000;2(4):184-9.

12. Friberg B, Jemt T, Lekholm U. Early failures in 4,641 consecutively placed Brånemark dental implants: a study from stage 1 surgery to the connection of completed prostheses. The International journal of oral \& maxillofacial implants. 1991;6(2):142-6.

13. Migliorança R, Coppedê A, Zamperlini M, Mayo T, Viterbo R, Lima D. Reabilitação da maxila atrófica sem enxertos ósseos: resultados de um novo protocolo utilizado em casos de edentulismo total. Rev Implant News. 2007;4(5):557-64.

14. Krekmanov L, Kahn M, Rangert B, Lindstrom $\mathrm{H}$. Tilting of posterior mandibular and maxillary implants for improved prosthesis support. The International journal of oral \& maxillofacial implants. 2000;15(3):405-14.
BISPO LB

SHITSUKA CDWM

USO DE

IMPLANTES

ANGULADOS NA

REABILITAÇÃO

ORAL:

PLANEJAMENTO

REVERSO

181
REV. OdONTOL.

Univ. Cid. São

Paulo

2017; 29(2):

$174-83$, MA I - AGO 
$B I S P O \quad L B$ SHITSUKA CDWM

USO DE

IMPLANTES

ANGULADOS NA

REABI LITAÇÃO

ORAL:

PLANEJAMENTO

REVERSO

182

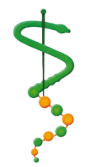

REV, ODONTOL.

UNIV, CID, SÃO

PAULO

$2017 ; 29(2):$

$174-83$, MAI - AGO
15. Hansen CA, DeBoer J, Woolsey GD. Esthetic and biomechanical considerations in reconstructions using dental implants. Dental clinics of North America. 1992;36(3):713-41.

16. Tabuse HE, Corrêa CB, Vaz LG. Comportamento biomecânico do sistema prótese/implante em região anterior de maxila: análise pelo método de ciclagem mecânica. Revista de Odontologia da UNESP. 2014;43(1):46-51.

17. Tarnow DP, Cho SC, Wallace SS. The effect of inter-implant distance on the height of inter-implant bone crest. Journal of periodontology. 2000;71(4):546-9.

18. Piattelli A, Scarano A, Piattelli M, Vaia E, Matarasso S. Hollow implants retrieved for fracture: a light and scanning electron microscope analysis of 4 cases. Journal of periodontology. 1998;69(2):185-9.

19. McDermott NE, Chuang SK, Woo VV, Dodson TB. Complications of dental implants: identification, frequency, and associated risk factors. The International journal of oral \& maxillofacial implants. 2003;18(6):848-55.

20. Almeida EO, Pellizzer EP. Biomecânica em prótese sobre implante relacionada às inclinações das cúspides e às angulações dos implantes osseointegrados: revisão de literatura. Rev odontol UNESP. 2008;37(4):321-7.

21. Weinberg LA. Reduction of implant loading with therapeutic biomechanics. Implant dentistry. 1998;7(4):277-85.

22. Weinberg LA, Kruger B. An evaluation of torque (moment) on implant/prosthesis with staggered buccal and lingual offset. The International journal of periodontics \& restorative dentistry. 1996;16(3):252-65.

23. Pereira BMF, Nóbilo MAA, Mesquita MF, Henriques GEP, Consani RLX, Silva MDMS, et al. Solução protética para implantes mal posicionados: relato de caso clínico. J Health Sci Inst. 2011;29(4):257-60.
24. Dixon DL, Breeding LC, Sadler JP, McKay ML. Comparison of screw loosening, rotation, and deflection among three implant designs. The Journal of prosthetic dentistry. 1995;74(3):270-8.

25. Bueno Torcato L, Tessarin GWL, Falcón-Antenucci RM, Lemos CAA, Pellizzer EP. Análise das tensões em diferentes conexões de implante/abutment. Revista de Cirurgia e Traumatologia Buco-maxilo-facial. 2016;16(1):7-12.

26. Chun HJ, Shin HS, Han CH, Lee SH. Influence of implant abutment type on stress distribution in bone under various loading conditions using finite element analysis. The International journal of oral \& maxillofacial implants. 2006;21(2):195-202.

27. Hermann C, Moro D, Bungenstab RM, Faot F, Sartori IAM, Thomé G. Sistema" attachment" bola mini para implantes angulados em sobredentaduras. Revista Gaúcha de Odontologia. 2007;55(3):311-4.

28. Mazetto F, Bastos ELdS, Accetturi F, Plese A. Solução alternativa para overdentures retidas por implantes com eixos diferentes de inserção-Caso Clínico. Revista libero-americana de Prótese Clínica e Laboratorial. 2003;5(27):402-6.

29. Jemt T, Book K, Linden B, Urde G. Failures and complications in 92 consecutively inserted overdentures supported by Branemark implants in severely resorbed edentulous maxillae: a study from prosthetic treatment to first annual check-up. The International journal of oral \& maxillofacial implants. 1992;7(2):162-7.

30. Duailibe-de-Deus C, Moura-Vieira J, João-Pedro G, Marzola C. Resolução cirúrgica e protética de implantes dentários instalados em posição desfavorável em região estética da maxila. Rev Odont (ATO). 2016;16(9):909-23. 
31. Berwanger E, Cacenotte D, Valle C, Lodi L, Rigo L. Técnica de instalação de implantes inclinados na reabilitação de maxila atrófica. Full Dent Sci 2014;6(21):33-8.

32. Verri F, Cruz R, Oliveira H, Lemos C, Almeida D, Batista V. Resolução protética para reabilitação de pacientes com implantes unitários inclinados na região maxilar anterior: relato de caso. Rev Odontol Araçatuba. 2015;36(2):49-54.

33. Matsumoto W, Hotta T, Antunes R, Reino D. Implante unitário anteriorprocedimentos de enxertia e provisionalização. Rev Bahiana de Odontol. 2016;7(1):63-73.

34. Antunes AA, Carvalho RWFd, Lucas Neto A, Loretto NRM, Silva EDdO. Utilização de implantes ósseointegrados para retenção de próteses buco-maxilo-faciais: revisão da literatura. Rev cir traumatol buco-maxilo-fac. 2008;8(2):9-14.

35. Chapman RJ. Principles of occlusion for implant prostheses: guidelines for position, timing, and force of occlusal contacts. Quintessence international (Berlin, Germany : 1985). 1989;20(7):473-80.

36. Weinberg LA. The biomechanics of force distribution in implant-supported prostheses. The International journal of oral \& maxillofacial implants. 1993;8(1):19-31.
37. Kaukinen JA, Edge MJ, Lang BR. The influence of occlusal design on simulated masticatory forces transferred to implant-retained prostheses and supporting bone. The Journal of prosthetic dentistry. 1996;76(1):50-5.

38. Moraes MCC, Moraes EJ, Elias CN. Análise de tensões em implantes osseointegrados por elementos finitos: variação da inclinação da cúspide e largura da mesa oclusal. Rev Bras Implant. 2002;8(2):21-6.

39. Sato Y, Shindoi N, Hosokawa R, Tsuga $\mathrm{K}$, Akagawa Y. A biomechanical effect of wide implant placement and offset placement of three implants in the posterior partially edentulous region. Journal of oral rehabilitation. 2000;27(1):15-21.

40. Akça K, Iplikçioğlu H. Finite element stress analysis of the influence of staggered versus straight placement of dental implants. The International journal of oral \& maxillofacial implants. 2001;16(5):722-30.

41. Gross MD, Nissan J. Stress distribution around maxillary implants in anatomic photoelastic models of varying geometry. Part II. The Journal of prosthetic dentistry. 2001;85(5):450-4.

42. Çaglar A, Aydin C, Ozen J, Yilmaz C, Korkmaz T. Effects of mesiodistal inclination of implants on stress distribution in implant-supported fixed prostheses. The International journal of oral \& maxillofacial implants. 2006;21(1):36-44.
BISPO LB

SHITSUKA CDWM

USO $D E$

IMPLANTES

ANGULADOS NA

REABILITAÇÃO

$O R A L$ :

PLANEJAMENTO

REVERSO

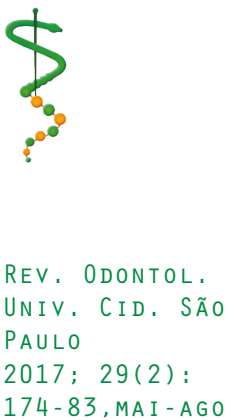

